University of South Florida

DIGITAL COMMONS

Digital Commons @ University of

@ UNIVERSITY OF SOUTH FLORIDA

South Florida

Rehabilitation and Mental Health Counseling

Faculty Publications

Rehabilitation and Mental Health Counseling

2009

\title{
Preventive Health Engineering in Earlier and Later Life
}

Johanna E.M.H. Bronswijk

Eindhoven University of Technology

William D. Kearns

University of South Florida, kearns@usf.edu

Follow this and additional works at: https://digitalcommons.usf.edu/mhs_facpub

\section{Scholar Commons Citation}

Bronswijk, Johanna E.M.H. and Kearns, William D., "Preventive Health Engineering in Earlier and Later Life" (2009). Rehabilitation and Mental Health Counseling Faculty Publications. 97.

https://digitalcommons.usf.edu/mhs_facpub/97

This Article is brought to you for free and open access by the Rehabilitation and Mental Health Counseling at Digital Commons @ University of South Florida. It has been accepted for inclusion in Rehabilitation and Mental Health Counseling Faculty Publications by an authorized administrator of Digital Commons @ University of South Florida. For more information, please contact digitalcommons@usf.edu. 


\title{
Preventive health engineering in earlier and later life
}

\author{
Johanna E.M.H. van Bronswijk PhD \\ Performance Engineering for Built Environments, \\ Department of Architecture, Building and Planning, \\ Eindhoven University of Technology, Eindhoven, The Netherlands \\ E: j.e.m.h.v.bronswijk@tue.nl \\ William D. Kearns PhD \\ Department of Aging and Mental Health Disparities, \\ Louis de la Parte Florida Mental Health Institute, \\ University of South Florida, Tampa, FL 33612, USA \\ E: kearns@fmhi.usf.edu
}

\begin{abstract}
J.E.M.H. van Bronswijk, W.D. Kearns. Preventive health engineering in earlier and later life. Gerontechnology 2009; 8(2):76-81; doi: 10.4017/gt.2009.08.02.005.00. Preserving autonomy and independence up to the highest ages calls for a major reduction in chronic conditions. By applying the Compressing Morbidity concept that concentrates the period of senescence near the end of life, the number of healthy years can be enlarged. Many chronic conditions are elicited by lifetime exposures to environmental factors, such as (indoor) air pollution (asthma, COPD, lung cancer), noise exposure (hearing disorders), or physically unbalanced work or sports (mobility disorders), to name a few. Unfortunately, in earlier life there is little interest in expected later health. Persuasive technology is useful here. Since, in the Western World, our environment is mainly man-made, improved technology has a major role in preventing noxious exposures to high-intensity light or noise, polluted air, or infested water, while respecting freedom of choice of individual persons. Ambient intelligence seems to be the best approach to realize these objectives, since it may take different exposures at various times under varying circumstances into account. Assessing costs and gains in health and longevity from an economic point of view is useful in showing societal sustainability of preventive measures to be taken at the regional level.
\end{abstract}

Key words: prevention, health engineering, life span phases, gerontechnology

Historically, a reduction in mortality has been followed by a reduction in fertility in the human population. After the fertility transition, the population as a whole has aged. Apparently this is happening on all continents, although not necessarily at the same pace or time frame ${ }^{1}$. With middle aged and older persons constituting the majority, the call for quality of life up to a high age is heard more loudly ${ }^{2,3}$. Preserving autonomy and independence up to high ages are two major determinants of perceived quality of life ${ }^{4}$. To translate this perception into reality calls for a large scale reduction in chronic conditions that contribute most to present morbidity ${ }^{5,6}$. Major chronic illnesses are about $70 \%$ preventable by changes in life style or technological environment ${ }^{5,7}$. The Compression of Morbidity paradigm ${ }^{8}$ envisions a reduction in cumulative lifetime morbidity through primary prevention by postponing the age of onset of disease or disability by a proportionately longer period in a lengthening life expectancy. It has become the dominant paradigm in health improvement programs for successful aging that may now increase the healthy life period with up to 10 years after interventions in different life phases. The possible role of preventive health engineering in compressing morbidity is the subject of this contribution. 


\section{LIFE STYLE}

In the health sciences the following indicators of chronic disease are recognized: coronary heart disease, stroke, type 2 diabetes, kidney disease, arthritis, osteoporosis, lung cancer, colorectal cancer, chronic obstructive pulmonary disease (COPD), asthma, depression, and oral health disorders. As risk factors for the related health outcomes the health literature includes life-style factors, such as tobacco smoking, physical inactivity, alcohol abuse, overweight and obesity, nutrition, and some life-style-resulting physiological effects: hypertension, elevated cholesterol levels, impaired glucose tolerance, and proteinuria. Also psychosocial factors (sense of control or resilience, social support and social exclusion, emotional wellbeing / stress) are mentioned as well as early life factors (maternal health, low birth weight, childhood infections, abuse and neglect). Other, mainly physical, environmental factors are commonly left out.

Compressing the morbidity of chronic conditions is largely seen as a result of intervention in life style. However, classical health promotion is quite ineffective in changing human behaviour, including that of older persons $^{10}$. One of the problems is that a person's interest in his/her health depends on the life phase $s /$ he is in. In early life $\left(1^{\text {st }}\right.$ [youth] and $2^{\text {nd }}$ [working \& family forming]), there is little interest in expected health in the $3^{\text {rd }}$ phase (active retirement) or $4^{\text {th }}$ one (frailty). However, prevention calls for action early in the lifespan since it includes primary prevention as well as secondary and tertiary prevention endeavors ${ }^{11}$. To the much used Technology Acceptance Model $(T A M)^{12}$, the emerging field of persuasive technology has been added, which is an upcoming branch of (health) engineering arising in the final decade of the last century ${ }^{13}$ which promises good results by endeavouring to change life styles through gaming as well as unobtrusive coaching activities. Persuasive technology is currently gaining slow acceptance in the preventive health sciences.

\section{ENVIRONMENTAL EXPOSURE}

Relevant environmental risk factors for developing chronic conditions go well beyond life style; they include the physical and social environment. Intense light and sound exposures are related to age-related losses in visual and hearing acuity ${ }^{14}$. Indoor air quality is an important determinant of the development of asthma, COPD and lung cancer ${ }^{7}$, while 'Legionella-low' potable and industrial water practically eliminates the risk of Veterans' disease $^{15}$. Ergonomics has revealed the long-term effects of unbalanced postures and movements on development of mobility disorders, not only in relation to a person's behaviour and tasks, but also as induced by faulty work and sports environments ${ }^{16}$. Social psychology has stressed the beneficial and detrimental influences of family and friends on the development of cognitive and emotional disorders ${ }^{11}$.

Below are some examples of the effects of air, water, light intensity and noise on physical health. Pulmonary, hearing and vision problems all contribute to a loss of independence of older persons.

\section{ENVIRONMENTAL ADJUSTMENTS}

In the Western World, our environment is mainly a man-made environment; therefore, improving technology has a major role in preventing noxious exposures. Ambient intelligence is grounded in ubiquitous computing and human-centric computer interaction; its systems and technologies are embedded in networked devices that are integrated into the environment. They are context aware, can be tailored to personal needs and wishes, and have both adaptive and anticipatory qualities ${ }^{17}$. Altering of the physical environment in order to prevent functional decline falls well within the construct of ambient intelligence.

\section{Inhaled air}

Common chronic diseases that are related to the quality of indoor air such as asthma, COPD and lung cancer have both hereditary and environmental causal factors. The 
known environmental factors include allergens (mainly derived from mites, pets and fungi), and non-allergenic products (arising from smoking and household activities) ${ }^{18}$. The effect of the noxious agents appears to be cumulative, starting very early in life. In atopic allergies new sensitizations are frequent, and the 8 -year remission rate varies from $8-29 \%{ }^{19}$.

Ventilation, heating and air treatment technologies to prevent mite and fungal growth and to remove most other pollutants are available and should be applied from the earliest age onward. However, adaptive management systems that respond to detected indoor pollution levels have not yet been implemented in dwellings ${ }^{7}$. Office building management systems include rudimentary static air management. A more dynamic and effective approach responsive to actual risk levels has not yet been introduced into ambient intelligence concepts ${ }^{20}$.

\section{Water}

Continuous quality monitoring and assessment of potable water has also not yet been implemented in ambient intelligence concepts nor in building management systems. Here, too, much stands to be gained by its introduction. In the developed world, management of Legionella bacteria causing Pontiac fever and Legionnaires' disease takes the highest priority, especially in countries such as the Netherlands, where chlorination of potable water is avoided due to environmental concerns ${ }^{15,21}$. The vulnerability of adults age 60-64 to this bacterium in shower water is increased 10 fold compared to ages 40-44, while at age 75-79 it rises more than 100 fold $^{21}$. Surviving victims of a major outbreak in the Netherlands have been followed for about a decade and showed a high prevalence of both chronic mental and physical conditions that forced people from work, leisure activities, and reduced their autonomy ${ }^{22,23}$. It is surprising that fully preventable Legionella risk does not hold prominent place in modern health engineering.

\section{Noise \& sound}

Hearing loss in older adults may be attributable to both environmental and genetic causes. Currently we do not know what proportion of hearing loss is preventable by avoiding intense sounds common to daily life, by silencing those technologies that produce noise, by using ear plugs, by changing life style, or by soundproofing man-made environments. However, ambient noise or noise pollution has a broader effect on health, ranging from disturbed concentration and sleep disruptions to the degradation of residential, social, working, and learning environments ${ }^{24,25}$. Static guidelines can never be formulated to take into account all these effects at all times. A more dynamic and responsive system having sensors and actuators is needed to guarantee a healthy sound/noise environment.

\section{Light intensity}

The eye continuously perceives ambient electromagnetic radiation in the visible range $(400-700 \mathrm{~nm})$, but is also exposed to the other frequencies. The visible band of radiation is interpreted by the brain as visual information and also establishes human circadian rhythm. Standards and guidelines for ambient lighting determine intensities needed for reading and other activities, or the light stimulation levels needed to maintain health ${ }^{26}$. Chronic effects of intense light may lead to eye damage, including age-related macular degeneration and cataract formation. Excessive light exposure among older adults is more risky than for younger individuals, since biological repair processes at the cellular level become less efficient with age $^{27}$. Outside the visible range, ultraviolet $\mathrm{B}$ has been found associated with cataract, a condition each older adult experiences sooner or $\operatorname{later}^{28}$. Cataracts diminish light falling on the retina and reduce the influence of visible light on circadian rhythms, leading to a decrease in quality of life. The optimal range of intensities of visible and invisible light and lighting appear to be dependent on age and environment, necessitating adaptable and adaptive options. 


\section{AUTOMATION AND FREEDOM OF CHOICE}

The mechanisms to manage the environments mentioned earlier require automated data collection and functional integration. The computerization of the home environment brings together concerns about privacy, sensitivity of data, and other ethical issues, for healthy, autonomous persons and for those affected with dementia. Current privacy policies and regulations lag behind technological developments, especially given society's move into an era of ambient intelligence that broadens the possibilities for data collection in kind, frequency and quantity ${ }^{29}$. Also, increasingly complex interface design limits personal control in ambient intelligence environments; the user has to trust the system sufficiently in order to work with it comfortably $12,30,31$. So called 'fear of (new) technology' is still wide-spread and can only be conquered by the combined efforts of psychology, technology and appropriate legislation, preferably as an international endeavour.

\section{INDUSTRIES INTEREST}

In a small sample of new products selected by organizations for presentation at the GerontechnoPlatform in Paris, and whose claims survived peer review (Table 1) a strong emphasis exists on health, but little attention has been paid to leisure, work, communication and governance of older adults. Most products mentioned ${ }^{2}$ appear to originate from technology vendors seeking an application for their product, so called 'technology push' initiatives. The ambitions of older adults are still not being used as the starting point for product development. For preventive health engineering, primary prevention is a need still unfilled. Preventive products concern secondary or tertiary prevention.

\section{Costs AND GAINS}

It is a challenge for gerontechnology, especially preventive health engineering, to show health improvements resulting directly from the combined actions of gerontological and technological research, design and engineering for improving daily environments in a sustainable way.
Table 1. New products mentioned in this issue ${ }^{2}$ as classified according to the gerontechnology impact matrix

\begin{tabular}{|c|c|c|c|c|c|c|c|}
\hline & \multicolumn{6}{|c|}{ Application domain } \\
\hline & & 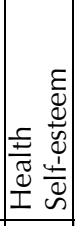 & 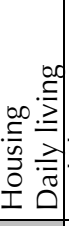 & 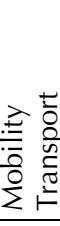 & 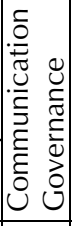 & 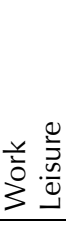 & $\frac{0}{\frac{\pi}{0}}$ \\
\hline \multirow{5}{*}{ 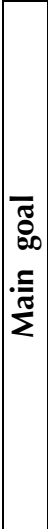 } & $\begin{array}{l}\text { Enrichment } \\
\text { Satisfaction }\end{array}$ & 1 & 0 & 2 & 2 & 1 & 6 \\
\hline & \begin{tabular}{|l} 
Prevention \\
Engagement
\end{tabular} & 3 & 1 & 0 & 0 & 0 & 4 \\
\hline & $\begin{array}{l}\text { Compensation } \\
\text { Substitution }\end{array}$ & 1 & 2 & 3 & 0 & 0 & 6 \\
\hline & $\begin{array}{l}\text { Care support } \\
\text { Care } \\
\text { organization }\end{array}$ & 4 & 2 & 1 & 0 & 0 & 7 \\
\hline & Totals & 9 & 5 & 6 & 2 & 1 & 23 \\
\hline
\end{tabular}

Assessing costs and gains at the population level is useful for showing societal sustainability of preventive health engineering measures. The first question to be answered is the monetary value of a healthy year. In 2001 the World Health Organization published its report on 'Macroeconomics and Health' in which the $\mathrm{WHO}$ accepts a value from up to 3 times the Gross National Product (GNP)/ capita as the socially acceptable worth of 1 extra healthy year in developed countries, to a value of only 1 times the GNP/capita for developing nations ${ }^{32}$. GNP/capita varies greatly; in 2007 from US\$ 110 (Burundi) to 77,370 (Norway) ${ }^{33}$, setting the maximum cost of technological interventions to gain 1 healthy year at $\approx U S \$ 100$ to $\approx U S \$ 230,000$, depending on country.

The next question to be answered is whether available preventive health engineering can be produced and implemented within the cost constraints mentioned above. For the Netherlands, Franchimon et al. ${ }^{7,15}$ showed that the cost of preventive engineering interventions affecting clean indoor air for all 
ages and Legionella-low potable water systems for the older years, remain below the $3 \times \mathrm{xNP} / \mathrm{capita}$ limit. However, these macroeconomic calculations require replication in other regions and for the effect of other noxious agents.

\section{ConcLusion}

It is clear from the economic figures that health quality is even more a cultural phenomenon than is apparent from its relationship to life style. Successful preventive health engineering depends on regional character- istics, and the results from one cultural or economic region are not easily generalized to another. A comprehensive search for cost-effective preventive health engineering technologies that can be applied locally, at the point of need and an estimate of their feasibility, is indicated. Macro-economic calculations will help the selection of feasible preventive health engineering measures in order to gain quality in daily environments, while respecting personal freedom of choice and societal sustainability.

\section{Acknowledgement}

This contribution has been presented in a symposium (Gerontechnology for optimal health in a multidisciplinary context) at the 19th IAGG World Congress of Gerontology and Geriatrics in Paris, July 2009.

\section{References}

1. Ní Bhrolcháin M, Dyson T. On causation in demography: issues and illustrations. Population and Development Review 2007;33(1):1-36; doi: 10.1111/j.17284457.2007.00157.x

2. Franco A, Bouma $H$, Cornet $G$, Mallea P. Gerontechnology at IAGG 2009 for optimal health in a multidisciplinary context. Gerontechnology 2009;8(2):63-67; doi: 10.4017/gt.2009.08.02.001.00.

3. Bouma H, Fozard JL, Bronswijk JEMH van. Gerontechnology as a field of endeavour. Gerontechnology 2009;8(2):68-75; doi: 10.4017/gt.2009.08.02.004.00

4. Placencia-Porrero I. The information society in demographically changing Europe. Gerontechnology 2007;6(3):125-128; doi: 10.4017/gt.2007.06.03.001.00

5. Fries JF. Compression of morbidity in the elderly. Vaccine 2000;18(16):1584-1589; doi: 10.1016/S0264-410X(99)00490-9

6. Fries JF. Frailty, Heart Disease, and Stroke: The Compression of Morbidity Paradigm. American Journal of Preventive Medicine 2005;29(5S1):164-168; doi: 10.1016/j. amepre.2005.07.004

7. Franchimon F, Ament AHJA, Pernot CEE, Knies J, Bronswijk JEMH van. Preventing chronic lung disease in an aging society by improved building ventilation: An economic assessment. Gerontechnology 2008;7(4):374-387; doi: 10.4017/ gt.2008.07.04.025.00

8. Fries JF. Aging, natural death, and the compression of morbidity. New England Journal of Medicine 1980;303(3):130-135

9. Australian Institute of Health and Welfare. Indicators for chronic diseases and their determinants. Catalogue number PHE 75. Canberra: AlHW; 2008

10. King AC, Rejeski WJ, Buchner DM. Physical activity interventions targeting older adults: A critical review and recommendations. American Journal of Preventive Medicine 1998;15(4):316-333; doi: 10.1016/ S0749-3797(98)00085-3

11. Fozard JL. Impacts of Technology Interventions on Health and Self-Esteem. Gerontechnology 2005;4(2):63-76; doi: 10.4017/ gt.2005.04.02.002.00

12. Oppenauer C. Motivation and needs for technology use in old age. Gerontechnology 2009;8(2):82-87; doi: 10.4017/ gt.2009.08.02.006.00

13. Kort YAW de, IJsselsteijn WA, Eggen $\mathrm{JH}$, Hoven EAWH van den. Persuasive gerontechnology. Gerontechnology 2005;4(3):123-127; doi: 10.4017/ gt.2005.04.03.001.00

14. Fozard JL. Gerontechnology and perceptual motor-function: New opportunities for prevention, compensation, and enhancement. Gerontechnology 2001;1(1):5-24; doi: 10.4017/gt.2001.01.01.002.00

15. Franchimon F, Loonen RCGM, Bronswijk JEMH van. The economic acceptability of monochloramine treatment of potable water in the Netherlands. In Franchimon F. Healthy building services for the 21st century. PhD thesis, Eindhoven University of Technology, Eindhoven; 2009; pp 29-39

16. Kelsey JL, Hochberg MC. Epidemiology of Chronic Musculoskeletal Disorders. Annual Review of Public Health 1988;9(1):379-401; doi:10.1146/annurev.pu.09.050188.002115

17. Aarts EHL, Marzano S. The new everyday: Views on ambient intelligence. Rotterdam: 010 Publishers; 2003 


\section{Health engineering}

18. Franchi $M$, Carrer $P$, Kotzias $D$, Rameckers EMAL, Seppänen O, Bronswijk JEMH van, Viegi G. Towards Healthy Air in Dwellings in Europe: The THADE Report. Brussels: EFA Central Office; http://ec.europa.eu/ health/ph_projects/2001/pollution/fp_pollution_2001_exs_02.pdf; retrieved May 15, 2009

19. Linneberg A. The allergic march in early childhood and beyond. Clinical and Experimental Allergy 2008;38(9):1419-1421; doi: 10.1111/j.1365-2222.2008.03063.x

20. Franchimon F, Brink M. Matching technologies of home automation, robotics, assistance, geriatric telecare, and telemedicine. Gerontechnology 2009;8(2):88-93; doi: 10.4017/gt.2009.08.02.007.00

21. Bronswijk JEMH van, Hasselaar E, Koren LGH. Legionella risk shows the need for guideline innovation; An example from the Netherlands. Gerontechnology 2001;1(1):65-68; doi: 10.4017/ gt.2001.01.01.008.00

22. Käss G, Hoffer N. Legionella .... een ramp!. 10 jaar Stichting Veteranenziekte. Betrokkenen vertellen hun verhaal. Deskundigen geven hun mening [Legionella ..... a disaster! Victims tell their story. Experts explain]. Stichting Veteranenziekte 2009

23. Lettinga KD, Verbon A, Weverling GJ, Schellekens JFP, Boer JW den, Yzerman EPF, Prins J, Boersma WG, Ketel RJ van, Prins JM, Speelman P. Legionnaires' disease at a Dutch flower show: Prognostic factors and impact of therapy. Emerging Infectious Diseases 2002;8(12):1448-1454; http://origin. cdc.gov/ncidod/eid/vol8no12/pdfs/02-0035. pdf; retrieved May 15, 2009

24. Moore BCJ. Hearing loss in the elderly and its compensation with hearing aids. Gerontechnology 2002;1(3):140-152; doi: 10.4017/ gt.2001.01.03.003.00
25. Goines L, Hagler L. Noise pollution: A modern plague. Southern Medical Journal 2007;100(3):287-294

26. Aarts MPJ, Westerlaken AC. Field study of visual and biological light conditions of independently-living elderly people. Gerontechnology 2005;4(3):141-152; doi: 10.4017/gt.2005.04.03.004.00

27. Sliney $\mathrm{DH}$. Ocular injury due to light toxicity. International Ophthalmology Clinics 1988;28(3):246-250; doi: 10.1097/00004397-198802830-00017

28. McCarty CA, Taylor HR. A review of the epidemiologic evidence linking ultraviolet radiation and cataracts. Developments in Ophthalmology 2002;35:21-31; doi: 10.1159/000060807

29. Hoof J van, Kort HSM, Markopoulos P, Soede M. Ambient intelligence, ethics and privacy. Gerontechnology 2007;6(3):155163; doi: 10.4017/gt.2007.06.03.005.00

30. Jordan N. Allocation of functions between man and machines in automated systems. Journal of Applied Psychology 1963;47(3):161-165; doi: 10.1037/h0043729

31. Ross P. Ethics and aesthetics in intelligent product and system design. PhD thesis, Eindhoven University of Technology, December 17, 2008

32. The commission on macroeconomics and health. Macroeconomics and health: investing in health for economic development. Geneva: World Health Organization, 2001; p 31; http://whqlibdoc.who. int/publications/2001/924154550x.pdf; retrieved May 13, 2009

33. Worldbank. World Development Indicators database, revised 24 April 2009: Gross national income per capita 2007, Atlas method and PPP; http://siteresources. worldbank.org/DATASTATISTICS/Resources/GNIPC.pdf; retrieved May 13, 2009 